\title{
Estimation of the specific enthalpy-temperature functions for plastering mortars containing hybrid mixes of phase change materials
}

\author{
Mohammad Kheradmand · Jose B. de Aguiar • \\ Miguel Azenha
}

Received: 22 June 2013/Accepted: 28 November 2013/Published online: 26 March 2014

(C) The Author(s) 2014. This article is published with open access at Springerlink.com

\begin{abstract}
The use of phase change materials (PCMs) for the building sector is increasingly attracting attention from researchers and practitioners. Several research studies forwarded the possibility of incorporating microencapsulated PCM in plastering mortars for building façades, in pursuit of increased energy efficiency associated with the heat storage capacity of PCM. However, most of these studies are centred in the use of a single type of PCM, which is bound to be more adequate for a given season of the year (e.g. winter or summer) than for all the seasons. The study proposed in this work regards the evaluation of the possibility of using more than one kind of PCM, with distinct melting ranges, here termed as hybrid PCMs, in plastering mortars, to achieve adequately advantageous performance in all seasons of the year. To characterize the PCM, the specific enthalpy and phase change temperature should be adequately measured. The main purpose of this study was to show the conceptual feasibility of combining PCMs in mortars and to evaluate the behaviour of the resulting mortars with differential scanning calorimeter. The results showed that the behaviour of the mortar that
\end{abstract}

5th International Congress on Energy and Environmental Engineering and Management (CIIEM).

M. Kheradmand $(\bowtie) \cdot$ J. B. de Aguiar

Department of Civil Engineering, C-TAC, University of Minho, Guimarães, Portugal

e-mail: m.kheradmand@civil.uminho.pt

J. B. de Aguiar

e-mail: aguiar@civil.uminho.pt

\section{Azenha}

Department of Civil Engineering, ISISE, University of Minho, Guimarães, Portugal

e-mail: miguel.azenha@civil.uminho.pt contains more than one type of PCM can be predicted through the superposition of effects of the independent PCMs and no interaction occurs between them. The knowledge obtained from the experimental testing established bases for a framework of numerical simulation of real-scale applications, which can be used to ascertain the feasibility of the hybrid PCM concept for decreases in energy consumption of heating/cooling demands in the buildings.

Keywords Phase change materials (PCM) . Microencapsulation - Mortar · Hybrid PCM . Calorimetry testing

\section{Introduction}

Energy consumption in buildings and the corresponding costs are two major challenging concerns in most countries worldwide. Therefore, decisions and measures aimed to increase energy efficiency become frequent in view of the importance of this issue. In buildings, a large portion of energy consumption corresponds to heating and cooling necessities [1]. The challenge is to achieve thermally comfortable constructions with minimum energy demand for cooling/heating. It is therefore important to investigate methods that can reduce the cooling/heating energy demand to maintain the internal thermal comfort.

One of the methods that is known to help in the reduction of peak cooling loads and stabilization of indoor temperature is the use of phase change materials (PCM) in buildings, taking advantage of the latent heat storage that is intrinsic to these materials [2-4].

The inclusion of PCMs in façade walls allows the building envelope to become an effective thermal energy 
storage system [5]. A well-designed thermal energy storage system can improve building operation by reducing the utilized energy to maintain indoor temperature ranges within acceptable comfort levels and shifting energy consumption apart from the peak load on the electrical grid [6]. The retardation of the energy utilization into the building depends on the weather conditions [7]. When ambient temperature increases and the PCM in the façade reaches its melting temperature, heat is absorbed during the phase change. Afterwards, when the ambient temperature reaches the solidification temperature of the PCM, it releases heat. Thus, the heat transfers between outdoor and indoor ambient of the building are decreased. This leads to an indoor thermal behaviour that tends to remain in the vicinity of the PCMs melting point temperature, thus increasing the thermal efficiency of the building. Adequate selection of the melting range is therefore important to guarantee the comfort level. Several studies have investigated methods for incorporating PCM into conventional building materials $[3,8-12]$.

One of the possible ways of using PCM in buildings consists in incorporating it into porous materials, such as plaster mortar or concrete. For such purpose, the PCM is incorporated into the mortar/concrete mix within microscale polymer capsules (microencapsulation). Microencapsulation of PCM is a process through which the particles of PCM (the core) are surrounded or coated with a continuous film of polymeric material (the shell). The dimensions are usually comprised between $300 \mu \mathrm{m}$ and $1 \mathrm{~mm}$ [13]. Simple spherical particles are the most common ones being fabricated and utilized [14]. In comparison with the direct incorporation and immersion methods, the microencapsulation of PCMs allows overcoming the following problems: corrosion on metals, decomposition and leakage [15].

For the use of PCM in building constructions, it is necessary to have a broad knowledge of the thermo-physical properties to support adequate design/optimization approaches. In this way, one of the most important properties to determine is the specific enthalpy and its relationship with temperature.

The main objective of this paper is the evaluation of the specific enthalpy performance of the PCM when incorporated into plastering mortar. The study is related to microencapsulated PCMs alone and also mortars that contain such PCMs (incorporated through microencapsulation). The mortars under study either contain a single type of incorporated PCM, or a blend of two distinct microencapsulated PCMs with distinct melting temperatures, here termed as hybrid PCM. It is intended to understand whether the mixing of two PCMs has a similar behaviour in regard to the superposition of effects of independent PCMs, and evaluate if any interaction is observed between them. In fact, no previous works were found in the literature regarding this subject. The results here reported will assist numerical simulation procedures of buildings with plastering mortars containing one or more types of PCM. Such numerical simulations can allow evaluating the feasibility of mortars containing PCMs in buildings and optimizing parameters for minimum energy consumptions.

\section{Experimental setup}

Materials and sample preparation

The studied materials were microencapsulated PCMs and mortars containing microencapsulated PCMs. Regarding the microencapsulated PCMs, three types of organic PCM paraffins were considered (Devan Mikrathermic D series): MC18 (melting temperature of $18{ }^{\circ} \mathrm{C}$ ), MC24 (melting temperature of $24{ }^{\circ} \mathrm{C}$ ) and $\mathrm{MC} 28$ (melting temperature of $28{ }^{\circ} \mathrm{C}$ ), with mean particle size of $\sim 18 \mu \mathrm{m}$. With these three types of PCMs, four samples were prepared for differential scanning calorimeter (DSC) tests: three samples that solely contained one type of PCM (MC18, MC24 or MC28) and one sample that contained a 50-50\% mass proportion mix of MC18 and MC28, here termed as MC18_28. The tested samples had average weight of $\sim 4 \mathrm{mg}$.

The experiments also involved the study of two mortars containing PCMs. The first mortar, here termed as SPCMM24, is a single PCM mortar and it contains MC24. The second mortar, here termed as HPCMM18_28, involves the combined use of MC18 and MC28 in the same total quantity as the first mortar contained only MC24. Detailed information on the mix proportions and adopted materials is provided in Table 1 . The formulation of the mortars was fixed in respect to criteria of the European Norm EN 998-1 [16]. The mortars were cast into cylindrical moulds, resulting in specimens with $1 \mathrm{~cm}$ height and $10 \mathrm{~cm}$ diameter. The few milligrams of mortars samples necessary for DSC testing were gathered by drilling of the hardened mortar.

Table 1 Mix proportions of formulations SPCMM24 and HPCMM18_28

\begin{tabular}{lll}
\hline Materials & \multicolumn{2}{l}{$\begin{array}{l}\text { Formulations (percentage of the } \\
\text { total weight of mortar) }\end{array}$} \\
\cline { 2 - 3 } & SPCMM24 & HPCMM18_28 \\
\hline Cement type I class 42.5R & 31.32 & 31.32 \\
Sand & 30.59 & 30.59 \\
Water & 18.79 & 18.79 \\
Super plasticizer (water reducer) & 0.94 & 0.94 \\
MC18 & - & 9.175 \\
MC24 & 18.34 & - \\
MC28 & - & 9.175 \\
\hline
\end{tabular}


Methodology and rationale

Generally, the standard measurement method for the analysis of many thermo-physical properties is the DSC [17]. A literature survey [17-19] revealed that there are different possibilities of operation methods to analyse PCM through DSC tests. The two most common methods are: the dynamic method, which corresponds to a constant heating rate and the step method, which consists in applying variable heating rates to the sample [18]. Barreneche et al. [19] state that both dynamic and step methods are suitable for testing organic materials such as paraffin. The drawbacks of the step method are related to its programme complexity, the fact that it is time consuming and the difficulties in data treatment/interpretation [20]. In this work, we present measurement data using the dynamic method.

The DSC calorimeter submits the sample to controlled temperatures and records the corresponding heat fluxes, thus providing information about temperatures and specific enthalpies associated with phase changes. From the heat flux, the specific heat can be obtained as a function of temperature, and the specific enthalpy is determined by integration procedures [17]. In this study, the methodology for specific enthalpy calculation follows the strategy adopted in [19].

The melting and freezing behaviours of the PCM were analysed by a DSC model Mettler Toledo DSC 822e. The DSC was calibrated with Indium standard [20], using a single point-calibration method. The DSC has an accuracy of $\pm 0.2{ }^{\circ} \mathrm{C}$ for temperature measurements. All the samples were tested within aluminium crucibles with volume of $40 \mu \mathrm{L}$ under nitrogen $\left(\mathrm{N}_{2}\right)$ atmosphere flow of $80 \mathrm{ml} \mathrm{min}{ }^{-1}$. The samples were weighted by an analytical balance with accuracy of $\pm 0.01 \mathrm{mg}$.

A constant heating/cooling rate of $1{ }^{\circ} \mathrm{C} \mathrm{min}-1$ was applied for all the samples, as recommended by [19, 21]. The temperature history was the following: (1) initial isothermal period at $-5^{\circ} \mathrm{C}$ for $5 \mathrm{~min}$; (2) dynamic heating up to $50{ }^{\circ} \mathrm{C}$ at a rate of $1{ }^{\circ} \mathrm{C} \mathrm{min}^{-1}$; (3) stabilization at $50{ }^{\circ} \mathrm{C}$ for $5 \mathrm{~min}$; (4) dynamic cooling to $-5{ }^{\circ} \mathrm{C}$ at a rate of $-1{ }^{\circ} \mathrm{C} \min ^{-1}$. Each sample was cycled once (heating and cooling).

The main purpose of this experimental process was to determine whether the specific enthalpy data calculated from DSC test can be used to predict the energy transferring performance of PCM materials incorporated into the plastering mortars.

Another question was whether the MC18_28 sample exhibited proportional effectiveness in the composite experiment, when compared with MC18 and MC28 (superposition and homogeneity issues). It is important to note that the DSC provides the heat flow $(\mathrm{mW})$ at each temperature for a specific sample mass. These values were converted to supplied energy $\left(\mathrm{kJ} \mathrm{kg}^{-1}\right)$, to allow comparisons between the calculated specific enthalpies of the several samples.

\section{Results and discussion}

\section{Results of PCM samples}

Table 2 shows the DSC results for different samples of tested PCM. None of the tested PCMs revealed melting temperatures (peak points) coinciding with the reference value indicated by the supplier, with maximum deviations reaching $3.74 \mathrm{~K}$. Furthermore, the difference between the melting peak temperature and the freezing peak temperature was of $3.29,4.5$ and $2.42 \mathrm{~K}$ for MC18, MC24 and $\mathrm{MC} 28$, respectively. This is coherent with reports of hysteretic behaviour of the phase change by Castellon et al. [17]. For the sample of MC18_28, the difference between the melting peak temperatures and the freezing peak temperatures was of 2.7 and $1.86 \mathrm{~K}$ for the phase changes corresponding to MC18 and MC28, respectively.

In the MC18_28 sample, the phase change melting temperatures were coherent with those of the components of the mix (MC18 and MC28). This indicates that, the mixing of two PCMs had similar behaviour to the independent PCMs and it can be inferred that they have not endured unexpected interactions with each other.

For illustrative purposes, Fig. 1 shows the DSC heating curves of MC18 and MC28 separately and also, superimposed graphically to the result of MC18_28 sample. It can be observed that, the specific enthalpy value of MC18_28 at $\sim 18{ }^{\circ} \mathrm{C}$ is almost half of the specific enthalpy of the MC18 sample at the same transition temperature. This is coherent with the fact that MC18_28 has half of the quantity of $18{ }^{\circ} \mathrm{C} \mathrm{PCM}$ when compared with MC18. A similar tendency is observed for the $28{ }^{\circ} \mathrm{C}$ transition (however with slightly higher deviation).

\section{Results of PCM mortar samples}

The DSC curves of SPCMM24 for heating and cooling processes shown in Fig. 2, are the peaks associated with melting and solidifying processes of PCM and can be clearly identified, in correspondence to the incorporated MC24. The detailed results for mortars incorporating the PCM microcapsules are shown in Table 3. From the observation of this table, it can be observed that the mortar sample SPCMM24 (powder) has values of onset temperature and endset temperature that are consistent with those of the MC24 sample (see Table 2), with small differences $(<1 \mathrm{~K})$. 
Table 2 Pure PCM DSC-specific enthalpy, onset and end temperatures for different PCM samples

\begin{tabular}{|c|c|c|c|c|c|c|c|c|c|}
\hline \multirow[t]{2}{*}{ Designation } & \multirow{2}{*}{$\begin{array}{l}\text { Weight } \\
(\mathrm{mg})\end{array}$} & \multicolumn{4}{|l|}{ Melting } & \multicolumn{4}{|l|}{ Freezing } \\
\hline & & $\begin{array}{l}\text { Onset } \\
\text { temp. }\left({ }^{\circ} \mathrm{C}\right)\end{array}$ & $\begin{array}{l}\text { End temp. } \\
\left({ }^{\circ} \mathrm{C}\right)\end{array}$ & $\begin{array}{l}\text { Specific } \\
\text { enthalpy } \\
\left(\mathrm{kJ} \mathrm{kg}^{-1}\right)\end{array}$ & $\begin{array}{l}\text { Peak temp. } \\
\left({ }^{\circ} \mathrm{C}\right)\end{array}$ & $\begin{array}{l}\text { Onset temp. } \\
\left({ }^{\circ} \mathrm{C}\right)\end{array}$ & $\begin{array}{l}\text { End temp. } \\
\left({ }^{\circ} \mathrm{C}\right)\end{array}$ & $\begin{array}{l}\text { Specific } \\
\text { enthalpy } \\
\left(\mathrm{kJ} \mathrm{kg}^{-1}\right)\end{array}$ & $\begin{array}{l}\text { Peak temp. } \\
\left({ }^{\circ} \mathrm{C}\right)\end{array}$ \\
\hline MC18 & 3.5 & 15.67 & 18.97 & 270.63 & 17.75 & 15.4 & 12.44 & 275.08 & 14.32 \\
\hline MC24 & 4.4 & 18.21 & 23.86 & 162.4 & 22.74 & 22.36 & 15.67 & 136.53 & 17.94 \\
\hline MC28 & 3.8 & 24.19 & 28.79 & 253.89 & 24.26 & 25.96 & 13.42 & 256.89 & 27.08 \\
\hline MC18_28 & 4.3 & $15.8,24.72$ & $18.29,27.8$ & $134.17,100.5$ & $17.61,27.08$ & $15.31,25.96$ & $13.51,22.62$ & $139.59,82.23$ & $14.7,24.78$ \\
\hline
\end{tabular}

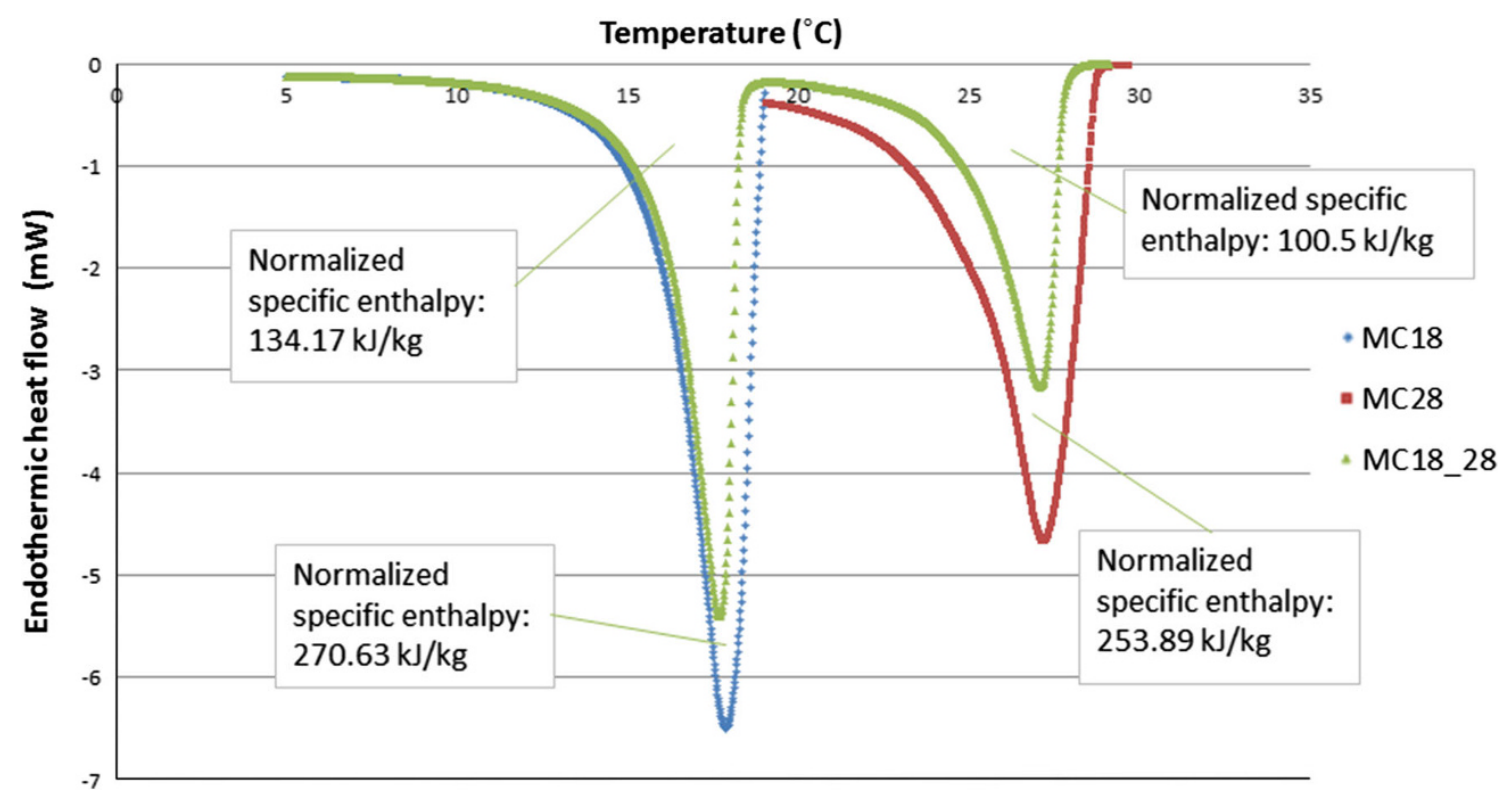

Fig. 1 Heating DSC curves for MC18, MC28 and MC18_28

Fig. 2 DSC test results of SPCMM24

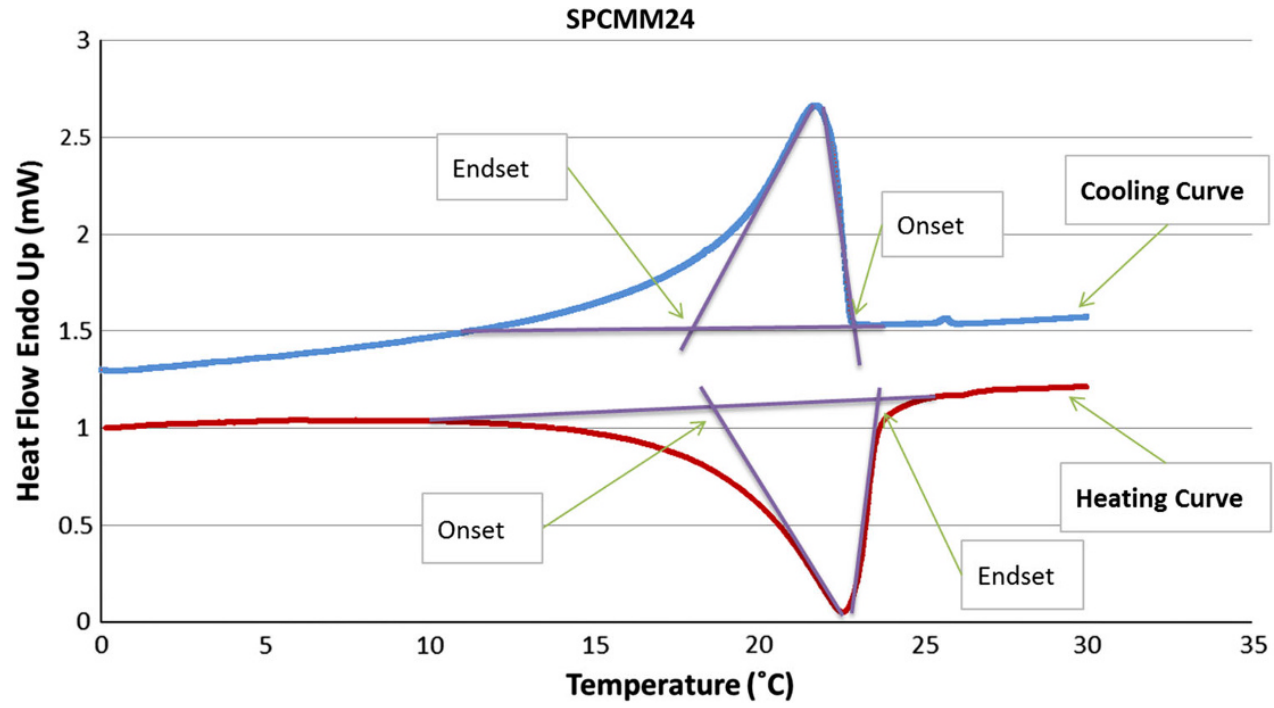

A comparison of the DSC curves of MC24 and SPCMM24 for the heating process is shown in Fig. 3. It can be seen that, in comparison with MC24, phase change temperatures of SPCMM24 are marginally shifted $(<1 \mathrm{~K})$. In regard to the latent heat storage calculations, the specific enthalpy $\left(H_{n}\right)$ values of MC24 and SPCMM24 in heating 
Table 3 PCM incorporated into mortar DSC-specific enthalpy, onset and end temperatures for different plaster mortars

\begin{tabular}{|c|c|c|c|c|c|c|c|c|c|}
\hline \multirow[t]{2}{*}{ Designation } & \multirow{2}{*}{$\begin{array}{l}\text { Weight } \\
(\mathrm{mg})\end{array}$} & \multicolumn{4}{|l|}{ Melting } & \multicolumn{4}{|l|}{ Freezing } \\
\hline & & $\begin{array}{l}\text { Onset temp. } \\
\left({ }^{\circ} \mathrm{C}\right)\end{array}$ & $\begin{array}{l}\text { End temp. } \\
\left({ }^{\circ} \mathrm{C}\right)\end{array}$ & $\begin{array}{l}\text { Specific } \\
\text { enthalpy } \\
\left(\mathrm{kJ} \mathrm{kg}^{-1}\right)\end{array}$ & $\begin{array}{l}\text { Peak temp. } \\
\left({ }^{\circ} \mathrm{C}\right)\end{array}$ & $\begin{array}{l}\text { Onset temp. } \\
(\mathrm{s})\left({ }^{\circ} \mathrm{C}\right)\end{array}$ & $\begin{array}{l}\text { End temp. } \\
\left({ }^{\circ} \mathrm{C}\right)\end{array}$ & $\begin{array}{l}\text { Specific } \\
\text { enthalpy } \\
\left(\mathrm{kJ} \mathrm{kg}^{-1}\right)\end{array}$ & $\begin{array}{l}\text { Peak temp. } \\
\left({ }^{\circ} \mathrm{C}\right)\end{array}$ \\
\hline SPCMM24 & 10.0 & 17.77 & 23.61 & 29.76 & 22.56 & 22.79 & 16.79 & 25.08 & 21.77 \\
\hline HPCMM18_28 & 15.9 & $15.36,24.32$ & $18.5,27.22$ & $24.61,18.41$ & $17.49,26.63$ & $24.5,13.99$ & $20.8,10.8$ & $25.66,15.09$ & $23.3,12.3$ \\
\hline
\end{tabular}

Fig. 3 Heating DSC curves of MC24 and SPCMM24



Table 4 Heat storage properties of PCMs and PCM mortars: measured values and extrapolated values (for mortars only)

\begin{tabular}{lllll}
\hline Designation & Melting process & \multicolumn{2}{l}{ Freezing process } \\
\cline { 2 - 3 } & $H_{n}\left(\mathrm{~kJ} \mathrm{~kg}^{-1}\right)$ & $H_{T}\left(\mathrm{~kJ} \mathrm{~kg}^{-1}\right)$ & $H_{n}\left(\mathrm{~kJ} \mathrm{~kg}^{-1}\right)$ & 136.53 \\
MC24 & 162.4 & - & $139.59,82.23$ & - \\
MC18_28 & $134.17,100.5$ & - & 25.08 & - \\
SPCMM24 & 29.76 & 29.78 & $25.66,15.09$ & 25.04 \\
HPCMM18_28 & $24.61,18.41$ & $24.60,18.43$ & $\left.\mathrm{~kJ} \mathrm{~kg}^{-1}\right)$ \\
\hline
\end{tabular}

process are 162.4 and $29.76 \mathrm{~kJ} \mathrm{~kg}^{-1}$, respectively. If proportionality is assumed between the latent heat capacity of the mortar and the latent heat capacity of the incorporated PCM, according to its mass fraction of PCM, the following calculation formula can be established:

$H_{T}=H_{\mathrm{pcm}} \times \frac{W_{\mathrm{pcm}} \%}{100}$

where $H_{T}$ is calculated latent heat for the mortar $\left(\mathrm{J} \mathrm{g}^{-1}\right)$, $H_{\mathrm{pcm}}$ is the latent heat of the embedded PCM, $W_{\mathrm{pcm}} \%$ is the weight percentage of PCM in the mix. Table 4 summarizes the measured specific enthalpies of the PCMs and mortars, together with the expectable specific enthalpies of the mortars calculated according to Eq. (1). As presented in Table 4 , the numerical extrapolated enthalpy values $\left(H_{T}\right)$ for SPCMM24, match the measured values quite closely in both melting and cooling processes. This indicates an adequate incorporation of PCM and the feasibility of the extrapolation procedure.

The DSC curves of the HPCMM18_28 for heating and cooling processes are shown in Fig. 4. The mortar sample HPCMM18_28 has a similar behaviour to the corresponding MC18 and MC28, for the onset temperatures and endset temperatures of the solid-liquid phase transition (heating process). Moreover, the peak melting temperatures of HPCMM18_28 occurred almost in the same position in 
Fig. 4 Results of DSC testing of on HPCMM18_28

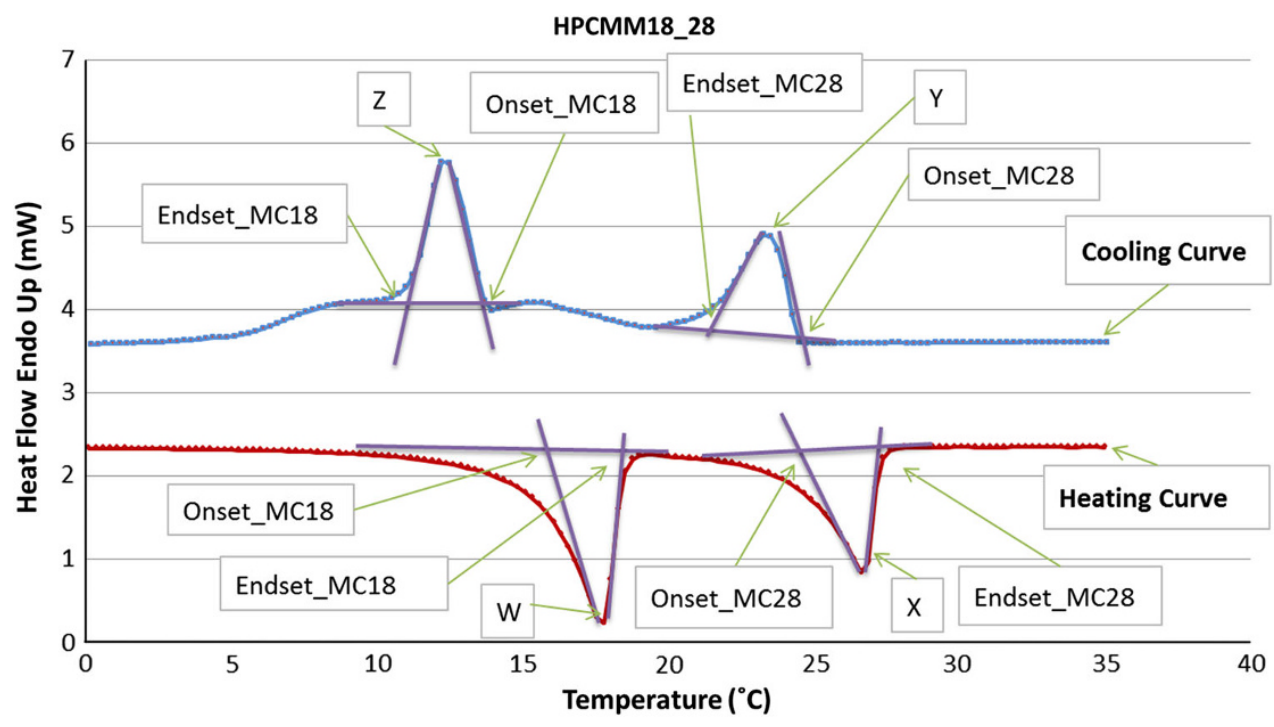

HPCMM18_28

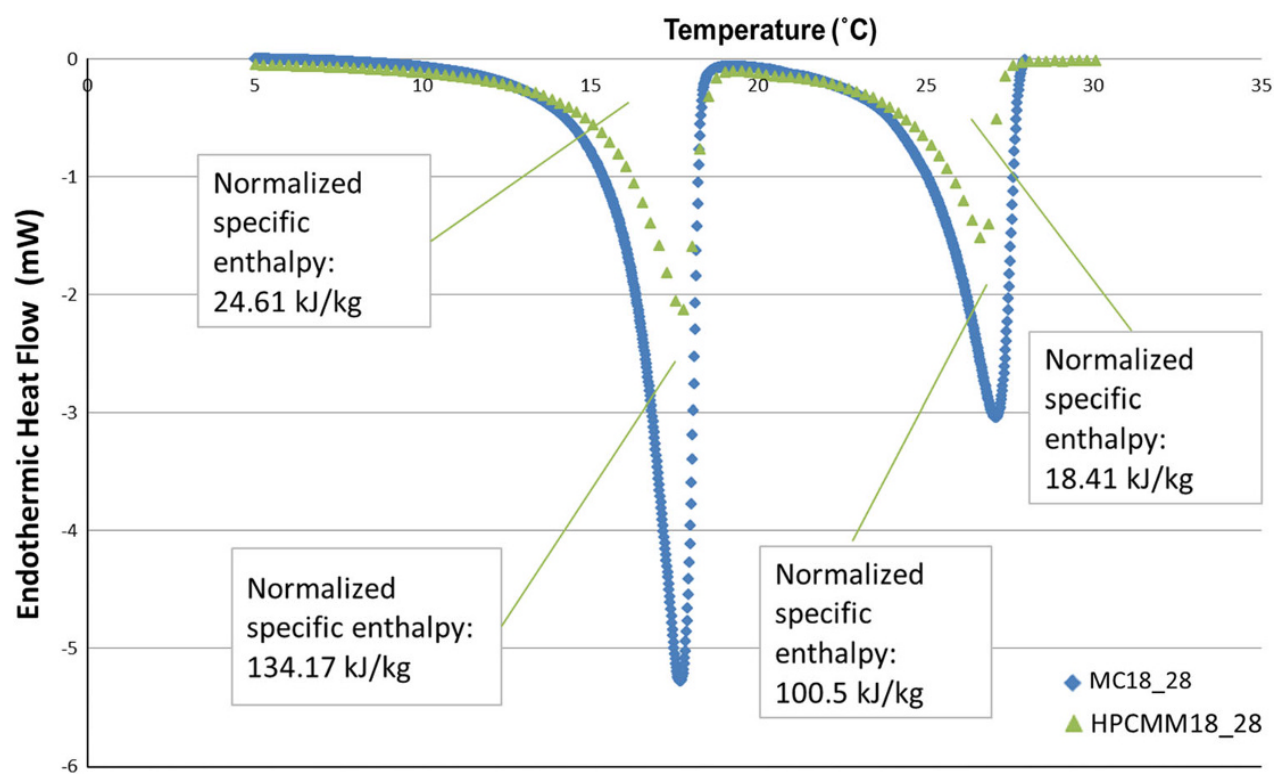

Fig. 5 Heating DSC curves of MC18_28 and HPCMM18_28 lead to different phase change temperatures of melting and freezing, for the corresponding PCM [22].

As presented in Table 4, the extrapolated $\left(H_{T}\right)$ values for HPCMM18_28 match the measured values quite closely in both melting and cooling processes. This is an excellent coherence, indicating an adequate proportionality of specific enthalpies even when hybrid mixes of PCM are used. For illustrative purposes, the relationship between the results of MC18_28 and HPCMM18_28 is shown in Fig. 5.

It can therefore be inferred that the several constituents of the mortar mixes seem to have none or negligible effect on the transitions of the microencapsulated PCMs (both on the temperatures and on the specific enthalpies). The observed differences can probably be justified by potential inaccuracies caused by the algorithm used to estimate onset and end temperatures, or by possible inhomogeneity within the samples. 


\section{Conclusions}

This study focused on specific enthalpy estimation and phase change temperature for PCM mortars and pure PCM samples as important parameters of thermal characterization. The results showed that the mix of two PCMs has a similar behaviour to the superposition of effects of independent PCMs. Therefore, it can be inferred that the two PCMs did not have thermal interaction with each other. Also, DSC tests of different samples showed that both plain microencapsulated paraffin samples (PCM) and plaster mortars containing microencapsulated PCM (SPCMM24 and HPCMM18_28) exhibit hysteretic behaviour of the phase change temperature in regard to heating/cooling cycles. Furthermore, it was observed that the specific enthalpy is linearly proportional to the mass fraction of PCM in the mortar sample as compared to the behaviour of plain PCM samples.

Finally, the numerically extrapolated enthalpy values $\left(H_{T}\right)$ for PCM mortars matched the measured values quite closely in both heating and cooling processes, indicating an adequate incorporation of PCM and the feasibility of the extrapolation procedure (principle of superposition). Using this superposition method, the necessity of testing hybrid PCM mortars for specific enthalpy can be avoided, as long as basic information about the thermal behaviour of each microencapsulated PCM is available. The use of this method can therefore be clearly advantageous when attempting to estimate latent heat properties of hybrid PCM mortars for numerical simulations targeted to optimize the types and temperatures of PCMs to incorporate in the plastering mortar.

Acknowledgments Funding provided by the Portuguese Foundation for Science and Technology (FCT) to the Research Project PTDC/ECM/102154/2008.

Conflict of interest The authors declare that they have no competing interests.

Authors' contributions MK carried out the experimental works, participated in the sequence alignment, and drafted the manuscript. JBdA participated in the sequence alignment, in the strategy of the study and provided requires materials. MA participated in the sequence alignment and in the strategy of the study. All authors read and approved the final manuscript.

Open Access This article is distributed under the terms of the Creative Commons Attribution License which permits any use, distribution, and reproduction in any medium, provided the original author(s) and the source are credited.

\section{References}

1. Constantinos, B.: European residential buildings and empirical assessment of the Hellenic building stock, energy consumption, emissions and potential savings. In: Environment, B.A. (ed.), vol. 42. Energy Information Administration, Washington (2007)
2. Cabeza, L., Castell, A., Barreneche, C., de Gracia, A., Fernández, A.: Materials used as PCM in thermal energy storage in buildings: a review. Renew. Sustain. Energy Rev. 15(3), 1675-1695 (2011)

3. Kuznik, F., Virgone, J., Roux, J.J.: Energetic efficiency of room wall containing PCM wallboard: a full-scale experimental investigation. Energy Build 40(1), 48-56 (2008)

4. Melhing, H., Cabeza, L.: Heat and cold storage with PCM, an up to date introduction into basics and applications. In: Mewes, D., Mayinger, F. (eds.) Heat and Mass Transfer. Springer, Berlin, Germany (2008)

5. Baetens, A., Petter, J.B., Gustavsen, A.: Phase change materials for building applications: a state-of-the-art review. Energy Build 42(9), 1361-1368 (2010)

6. Sarı, A., Sarı, H., Önal, A.: Thermal properties and thermal reliability of eutectic mixtures of some fatty acids as latent heat storage materials. Energy Convers. Manag. 45(3), 365-376 (2004)

7. Zhou, G., Zhang, Y., Zhang, Q., Lin, K., Di, H.: Performance of a hybrid heating system with thermal storage using shape-stabilized phase-change material plates. Appl. Energy 84, 1068-1077 (2007)

8. Shilei, L., Guohui, F., Neng, Z.: Experimental study and evaluation of latent heat storage in phase change materials wallboards. Energy Build. 39(10), 1088-1091 (2007)

9. Castell, A., Martorell, I., Medrano, M., Pérez, G., Cabeza, L.: Experimental study of using PCM in brick constructive solutions for passive cooling. Energy Build 42(4), 534-540 (2010)

10. Kuznik, F., Virgone, J.: Experimental assessment of a phase change material for wall building use. Appl. Energy 86, 2038-2046 (2009)

11. Ahmad, M., Bontemps, A., Salle'e, H., Quenard, D.: Thermal testing and numerical simulation of a prototype cell using light wallboards coupling vacuum isolation panels and phase change material. Energy Build. 38, 673-681 (2006)

12. Vaz Sá, A., Azenha, M., de Sousa, H.A.S.: Thermal enhancement of plastering mortars with phase change materials: experimental and numerical approach. Energy Build 49, 16-27 (2012)

13. Tyagi, V., Kaushik, S., Tyagi, S., Akiyama, T.: Development of phase change materials based microencapsulated technology for buildings: a review. Renew. Sustain. Energy Rev 15(2), 1373-1391 (2011)

14. Hawladera, M., Uddin, M., Khin, M.: Microencapsulated PCM thermal-energy storage system. Appl. Energy 74, 195-202 (2003)

15. Zhao, C., Zhang, G.: Review on microencapsulated phase change materials (MEPCMs): fabrication, characterization and applications. Renew. Sustain. Energy Rev 15, 3813-3832 (2011)

16. EN998-1, i.S.E.: Specification for mortar masonry. Part 1: rendering and plastering mortar. In: Brussels (2010)

17. Castellon, C., Gunther, E., Mehling, H.: Determination of the enthalpy of PCM as a function of temperature using a heat-flux DSC: a study of different measurement procedures and their accuracy. J Energy Res 32, 1258-1265 (2008)

18. Gunther, E., Hiebler, E., Mehling, H.: Enthalpy of phase change materials as a function of temperature: required accuracy and suitable measurement methods. Int. J. Thermophys 30, 1257-1269 (2009)

19. Barreneche, C., Solé, A., Miróa, L., Martorella, I., Fernándezb, I., Cabeza, L.: Study on differential scanning calorimetry analysis with two operation modes and organic and inorganic phase change material (PCM). Thermochimica Acta 553, 23-26 (2013)

20. Günther, E., Hiebler, S., Mehling, H.: Determination of the heat storage capacity of PCM and PCM-objects as a function of temperature. Paper presented at the ECOSTOCK measurements, N.M.I.f. c.a.b.: Indium-DSC Calibration Standard. In: NIST-2232. UK (2010)

21. Zhang, D., Tian, S., Xiao, D.: Experimental study on the phase change behavior of phase change material confined in pores. Sol. Energy 81, 653-660 (2007)

22. Gowreesunker, B.: Effectiveness of CFD simulation for the performance prediction of phase change building boards in the thermal environment control of indoor spaces. Build. Environ 59, 612-625 (2012) 